\title{
The suppression of kindling with low-frequency brain stimulation: Magnitude of important contributors
}

\author{
JOHN GAITO \\ York University, Downsview, Ontario, Canada
}

\begin{abstract}
In two preceding papers (Gaito, 1985a, 1985b), I presented statistical data for two important variables in the suppression of kindling behavior (duration of stimulation and intertrial intervals). In this article, the relative contribution of each of these (plus other reliable variance components) is contrasted with the associated error components. In both cases, reliable variance contributed a substantial proportion of the overall variance, whereas lesser amounts of variance were associated with error components when suppression was complete. The overall results suggest that the suppression process is a transient time-dependent one whose magnitude decreases with short durations of stimulation and with long intertrial intervals.
\end{abstract}

In a preceding paper (Gaito, 1985a), the effect of various durations of stimulation with $1-\mathrm{Hz}$ or $3-\mathrm{Hz}$ sine waves on $60-\mathrm{Hz}$ kindling behavior was indicated. A second paper provided the results of varying intervals between $1-\mathrm{Hz}$ and $60-\mathrm{Hz}$ stimulation (Gaito, 1985b). In this paper, the magnitude of these important variables is evaluated via statistical analyses.

\section{RESULTS}

\section{Duration Variable}

The durations of stimulation used were $0,5,15,30$, $60,120,180,300$, and $600 \mathrm{sec}$ (Gaito, 1985a). The results for the $1-\mathrm{Hz}$ and $3-\mathrm{Hz}$ stimulation effects were similar. Thus, statistical data are presented only for the $1-\mathrm{Hz}$ events.

To determine the magnitude of the duration effect, I used a type of intraclass correlation (Haggard, 1958), the Gaito Utility Coefficient (Uc) (Gaito, 1958, 1973). The obtaining of these coefficients can be illustrated by using the first effective threshold intensity ETI $_{1}$ point only in a simple one-factor ANOVA design with the data as shown in Table 1.

The Uc values for separate ETI points are shown in Table 2 and represent proportion of variances. The $F$ values are significant at $\mathrm{ETI}_{2}, \mathrm{ETI}_{3}$, and $\mathrm{ETI}_{4}$. As the $\mathrm{F}$ values increase from 1.34 at $\mathrm{ETI}_{1}$ to 25.61 at $\mathrm{ETI}_{4}$, the Uc values for the durations dimension increase from .046 to .779 , and the error decreases from .954 to .221 . From this table, it appears that the sharpest effect of the 1-Hz stimulation duration variable is between $\mathrm{ETI}_{1}$ and $\mathrm{ETI}_{2}$. The magnitude reaches a stable point at $\mathrm{ETI}_{3}$. This stability

The author thanks Judith Emslie for calculating some of the statistics reported in this paper. The author's mailing address is: Department of Psychology, York University, 4700 Keele Street, Downsview, Ontario, Canada M3J 1P3.
Table 1

Utility Coefficient Analysis for ETI

\begin{tabular}{lccc}
\hline \multicolumn{1}{c}{ Source } & MS & F & E(MS) \\
\hline Durations (d) & 3549 & $1.34 *$ & $\sigma_{\mathrm{e}}^{2}+\mathrm{n} \sigma_{\mathrm{d}}^{2}$ \\
S/D(e) & 2647 & & $\sigma_{\mathrm{e}}^{2}$ \\
\hline
\end{tabular}

Note $-2647=\sigma_{\mathrm{e}}^{2} ; \quad \mathrm{n}=7 ; \quad 3549=\sigma_{\mathrm{e}}^{2}+7 \sigma_{\mathrm{d}}^{2} ; \quad 3549=2647+7 \sigma_{\mathrm{d}}^{2}$; $\sigma_{\mathrm{d}}^{2}=902 / 7=129 ; \sigma_{\mathrm{e}}^{2}+\sigma_{\mathrm{d}}^{2}=2649+129=2778 ; \mathrm{U}_{\mathrm{cd}}=129 / 2778=.046 ;$ $\mathrm{U}_{\mathrm{ce}}=2649 / 2778=.954$. $* \mathrm{~F}$ value required to reject $\mathrm{H}_{0}$ is 2.09 , with df of 8 and 57.

Table 2

Utility Coefficients Over the Four ETI Determinations, Separately

\begin{tabular}{crcl}
\hline Determination & \multicolumn{1}{c}{$\mathrm{F}$} & $\mathrm{U}_{\mathrm{cd}}$ & $\mathrm{U}_{\mathrm{ce}}$ \\
\hline $\mathrm{ETI}_{1}$ & 1.34 & .046 & .954 \\
$\mathrm{ETI}_{2}$ & 6.46 & .438 & .562 \\
$\mathrm{ETI}_{3}$ & 21.21 & .743 & .257 \\
$\mathrm{ETI}_{4}$ & 25.61 & .779 & .221 \\
\hline
\end{tabular}

Note $-U_{c d}=U c$ values for the durations dimension; $U_{c e}=$ the error.

Table 3

Uc Values Over Four ETI Points In One Analysis

\begin{tabular}{|c|c|c|c|}
\hline \multicolumn{2}{|c|}{$\begin{array}{l}\text { Between-Subjects } \\
\text { Components }\end{array}$} & \multicolumn{2}{|c|}{$\begin{array}{l}\text { Within-Subjects } \\
\text { Components }\end{array}$} \\
\hline$\overline{\sigma_{\mathrm{d}}^{2}}$ & .336 & $\overline{\sigma_{\mathrm{E}}^{2}}$ & 142 \\
\hline$\sigma_{\mathrm{s}}^{2}$ & .208 & $\begin{array}{l}\sigma_{\mathrm{dE}}^{2} \\
\sigma_{\mathrm{er}}^{2}\end{array}$ & $\begin{array}{l}.163 \\
.151\end{array}$ \\
\hline
\end{tabular}

Note $-\sigma_{\text {er }}^{2}$ is the reduced error variance (i.e., experimental error after $\sigma_{s}^{2}$ is removed).

may be due to our procedure of not increasing the stimulation intensity beyond $200 \mu \mathrm{A}$, thus decreasing the probability of high ETI values.

Table 3 shows the Uc values for the analysis using all ETI points. This analysis is a partially hierarchal design with durations (D) and subjects (S) within durations as between-subjects sources, and ETI determinations (E), $E \times$ interval (I), and $S \times E / D$ as within-subjects sources. 
The F tests of D, E, and DE were significant ones. The Uc values of components for D (.336), E (.142), and DE (.163) are sources of reliable variance and sum to .641; the two error components have Uc values of .208 and .151 , summing to .359 .

The interaction of durations and ETI determinations had a moderate Uc value of .163. This value shows the differential effect of the various durations over the ETI determinations. There is no effect with the control and the 5-sec groups, a moderate effect with durations up to $120 \mathrm{sec}$, and greater suppression with durations beyond that time period.

\section{Intertrial Intervals}

The intertrial intervals with $1-\mathrm{Hz}$ and $60-\mathrm{Hz}$ stimulation were $1,3,24,72,120$, and $336 \mathrm{~h}$. There was also a control group that received only $60-\mathrm{Hz}$ sine waves (Gaito, 1985b).

Because of long intertrial intervals for rats in the 5- and 14-day experiments, these rats were run only for ETI and $\mathrm{ETI}_{2}$ determinations. Others were available for all determinations to $\operatorname{ETI}_{4}(1,3,24,72 \mathrm{~h}$, and controls). Table 4 shows the Uc values for these data.

For $\mathrm{ETI}_{1}$ and $\mathrm{ETI}_{2}$ determinations, the reliable variance components $\left(\sigma_{\mathrm{t}}^{2}\right.$, intertrial intervals; $\sigma_{\mathrm{E}}^{2}$, ETI points; $\sigma_{\mathrm{tE}}^{2}$, interaction) summed to .240 , and error variance $\left(\sigma_{\mathrm{s}}^{2}, \sigma_{\mathrm{er}}^{2}\right)$ accounted for .760. Thus with only two ETI determinations involved, the three intervals of 72, 120, and $336 \mathrm{~h}$ (which showed little or no suppression) reduced the magnitude of Uc values. With determinations through $\mathrm{ETI}_{4}$, the different trends by the control, 1-, 3-, 24-, and 72-h groups contributed increased magnitude (.635) for the three reliable variance components. The unreliable variance components $\left(\sigma_{\mathrm{s}}^{2}, .176\right.$, and $\left.\sigma_{\mathrm{er}}^{2}, .189\right)$ provided a sum of .365. The interaction component was substantial (.295); this contribution was due to the four trends: little or no effect for control and 72-h groups; modest effect for 24-h group; great effect for 1-h group; greatest effect for 3-h group.

\section{Duration and Intertrial Intervals}

The Uc values for $\mathrm{D}$ and $\mathrm{D} \times \mathrm{E}$ are not exactly comparable to those for $I$ and for $I \times E$ because the values are obtained from two separate analyses. However, the sum of the two Uc values for the interval analysis $(.278+.295$ $=.573)$ and the error components $(.176+.189=.365)$ are

Table 4

Uc Values For Intertrial Intervals Analysis

\begin{tabular}{|c|c|c|}
\hline & & $\mathrm{ETI}_{1}$ to $\mathrm{ETI}_{4}$ \\
\hline \multicolumn{3}{|c|}{ Between-Subjects Components } \\
\hline$\sigma_{\mathrm{t}}^{2}$ & .125 & .278 \\
\hline$\sigma_{s}^{2}$ & .445 & .176 \\
\hline \multicolumn{3}{|c|}{ Within-Subjects Components } \\
\hline$\sigma_{\mathrm{E}}^{2}$ & .005 & .062 \\
\hline$\sigma_{\mathrm{tE}}^{2}$ & .110 & .295 \\
\hline$\sigma_{\mathrm{er}}^{2}$ & .315 & .189 \\
\hline
\end{tabular}

$\overline{\text { Note }-t=\text { intervals; } s=\text { subjects; } E=E T I \text { determinations; } \text { er }=\text { reduced }}$ error. grossly similar to those from the durations analysis $[(.336+.163=.499)$ and $(.208+.151=.359)]$. Thus, these data (plus observations throughout a number of experiments) suggest that the durations and intervals contributions are approximately equal in the suppression process.

\section{THE SUPPRESSION EFFECT}

The duration and intertrial intervals dimensions are the main contributors for the suppression event. By manipulating these variables, we can "turn on" or "turn off", kindling behavior. Likewise, kindling behavior can be prevented before development (Gaito, 1982; Gaito \& Gaito, 1980) as well as after it is present.

Not only $1-\mathrm{Hz}$ and $3-\mathrm{Hz}$ frequencies produce suppression of kindling behavior. Even $60-\mathrm{Hz}$ stimulation used in a 60-60-60 sequence will produce a modest amount of interference. Moderate amounts of suppression occur with $30-\mathrm{Hz}$ and $10-\mathrm{Hz}$ stimulations. Great suppression results with 1-, 3-, and 5-Hz stimulations. Drastic interference is present with $.1, .01$, and .001 sine wave currents.

The exact basis for the suppression effect is not clear at this time. Presumably, it involves some modification of the brain process responsible for kindling, or else another process is developed that is antagonistic to the brain-kindling process.

One possible basis for the suppression effect is that lesions are produced by the low-frequency stimulation, and the damage raises the threshold for kindled responses. However, this explanation does not seem appropriate. Our histological analyses in the early research indicated that the tissue around the electrode tips of rats subjected to intensities of $200 \mu \mathrm{A}$ or lower with $1-\mathrm{Hz}$ or $3-\mathrm{Hz}$ current appeared similar to that of rats subjected only to $60-\mathrm{Hz}$ stimulation. Obviously, such analyses are of gross nature and could miss subtle lesions.

A more important consideration is the apparently transient nature of the suppression effect, in that a time decay of the suppression event is indicated under certain conditions. This decay is suggested by data that indicate that experimental rats convulse at, or near, the ETI ${ }_{1}$ point after 15 or 16 days of nonstimulation following the $\mathrm{ETI}_{4}$ determination. Furthermore, the above results with the intertrial intervals dimension indicate a time-dependent process with the interference reduced, or lost, for a $72-\mathrm{h}$ or longer interval.

A strong indication that tissue damage is not the basis for the suppression process was presented by Gaito (1981). Some rats were lesioned in the amygdala by direct current (dc) stimulation. These rats developed high ETI values on one trial and these thresholds did not change over time. In contrast, the $1-\mathrm{Hz}$ stimulated group experienced gradual increases in ETI values but returned to, or near, ETI $_{1}$ levels after 15 or more days of nonstimulation.

The suppression effect probably involves an inhibitory process similar to that reported by Mucha and Pinel (1977). It also appears to be a transient event like the tran- 
sient interference ("after effect") described by McIntyre and Goddard (1973). These transient aspects were in sharp contrast to the kindling process which was relatively permanent (Gaito, 1976; Goddard, McIntyre, \& Leech, 1969; Racine, 1978).

These interference or suppression effects ultimately might have important implications relative to the kindling effect and to brain function in general. Furthermore, a frequency that can suppress convulsions induced by another frequency eventually might prove worthwhile as a potential anticonvulsant in some types of human epilepsy.

\section{REFERENCES}

Garto, J. (1958). The Bolles-Messick coefficient of utility. Psychological Reports, 4, 595-598.

GAITo, J. (1973). Introduction to analysis of variance procedures. New York: MSS Corp.

GaITo, J. (1976). The kindling effect as a model of epilepsy. Psychological Bulletin, 83, 1097-1109.

GaITo, J. (1981). The effect of low frequency and direct current stimulation on the kindling phenomenon in rats. Canadian Journal of Neurological Sciences, 8, 249-253.
GaIto, J. (1982). The effect of prior treatment with $1-\mathrm{Hz}$ stimulation on the kindling phenomenon in rats. Bulletin of the Psychonomic Society, 19, 108-110.

GaITO, J. (1985a). The suppression of kindling with low-frequency brain stimulation: Statistical data with duration variable. Bulletin of the Psychonomic Society, 23, 332.

GaITo, J. (1985b). The suppression of kindling with low-frequency brain stimulation: Statistical data with intertrial intervals variable. Bulletin of the Psychonomic Society, 23, 421.

GaIto, J., \& GaIto, S. T. (1980). Prior treatment with 1-Hz stimulation retards the development of kindling induced by $60-\mathrm{Hz}$ stimulation. Bulletin of the Psychonomic Society, 15, 351-353.

Goddard, G. V., McInTyre, D. C., \& LeECh, C. K. (1969). A permanent change in brain function resulting from daily electrical stimulation. Experimental Neurology, 25, 295-330.

HAGGARD, E. A. (1958). Intraclass correlation and the analysis of variance. New York: Dryden.

MCINTYRE, D. C., \& GoDDARD, G. V. (1973). Transfer, interference and spontaneous recovery of convulsions kindled from the rat amygdala. Electroencephalography \& Clinical Neurophysiology, 35, 533-543.

Mucha, R. F., \& Pinel, J. P. J. (1977). Postseizure inhibition of kindled seizure. Experimental Neurology, 54, 266-282.

Racine, R. (1978). Kindling: The first decade. Neurosurgery, 3, 234-252.

(Manuscript received for publication March 26, 1985.) 